\title{
SECAGEM DE CEVADA (Hordeum vulgare): ANÁLISE DA DIFUSIVIDADE EFETIVA
}

\author{
G. ALBINI, H. PERAZZINI, F. B. FREIRE e J. T. FREIRE \\ Universidade Federal de São Carlos, Departamento de Engenharia Química \\ E-mail para contato: freire@ufscar.br
}

\begin{abstract}
RESUMO - A cevada é um dos cereais mais utilizados no processo de maltagem, sendo de grande interesse econômico para as indústrias cervejeiras. Faz-se a secagem dos grãos para diminuir a umidade e evitar a deterioração do produto. No presente trabalho é apresentado um estudo experimental da secagem de cevada em um secador de leito fixo e camada delgada com escoamento ascendente de ar aquecido em diferentes condições operacionais, obtendo dados de umidade em função do tempo. Os dados foram tratados segundo a abordagem a uma fase, na qual o modelo difusivo foi resolvido analiticamente considerando a difusividade efetiva como parâmetro constante ou como variável. Os resultados indicaram que a hipótese de difusividade efetiva constante não é realista. Considerando a difusividade efetiva como parâmetro variável, a simulação representou melhor os dados experimentais.
\end{abstract}

\section{INTRODUÇÃO}

A cevada (Hordeum vulgare ) é um cereal de inverno, ocupa a quinta posição de importância econômica no mundo. O grão é utilizado na produção de bebidas, como cerveja e destilados, na composição de farinhas para panificação, na produção de medicamentos e nas fórmulas de produtos dietéticos. É também utilizada como alimentação animal, forragem verde, e na fabricação de ração (Brasil, 2013). No Brasil, de acordo com Mori e Minella (2013), a malteação é a principal aplicação econômica da cevada. Do total produzido anualmente, $75 \%$ é para fabricação de malte, e 95\% deste é destinado a produção de cerveja. O conteúdo de umidade da cevada sofre modificações devido a fatores climáticos, temporais e genéticos, podendo variar de $13 \%$ a $25 \%$ (Tunes et al., 2010). O armazenamento dos grãos é considerado adequado quando o conteúdo de umidade é inferior a 12\% (base úmida). Para períodos mais longos de armazenamento, um conteúdo de umidade de $10 \%$ é o mais indicado (Briggs et al., 2004). Segundo Kunze (2004), quando a cevada é armazenada úmida, ela perde sua capacidade germinativa e produz um malte de má qualidade. Portanto, cevada contendo mais do que $12 \%$ de umidade deve passar pelo processo de secagem antes do armazenamento.

Durante o processo de secagem, a umidade é removida sob ação de diferentes mecanismos de transferência de calor e massa. Devido à complexidade dos fenômenos de transporte, a compreensão destes fenômenos depende de investigações a partir de estudos específicos e, neste sentido, o estudo da cinética de secagem é de fundamental importância. Visando contribuir para o desenvolvimento do processo de secagem, este trabalho tem por objetivo investigar os mecanismos de transporte de umidade que se estabelecem durante a secagem de grãos de cevada em um secador de leito fixo e camada delgada sob diferentes valores de temperatura e velocidade 
do ar.

\section{MODELO DIFUSIVO}

No processo de secagem, a umidade é removida do sólido e transferida para uma fase gasosa insaturada sob a ação de diferentes mecanismos de transporte de calor e massa. Para se obter informações quantitativas a respeito do transporte de umidade, é necessário a determinação dos parâmetros de transporte de massa. A difusividade efetiva é um parâmetro mássico tradicionalmente estimado através do modelo difusivo fundamentado na Segunda Lei de Fick.

\subsection{Difusividade efetiva constante}

Na secagem em camada delgada, uma vez que o tempo de residência é considerado curto e o equilíbrio térmico é atingido rapidamente, a variação de umidade e temperatura da fase gasosa em todo o leito pode ser considerada desprezível, sendo apenas o balanço de massa para a água contida na fase sólida considerado na modelagem do processo. A modelagem matemática da transferência de umidade em meios porosos pode ser convenientemente tratada através da Segunda Lei de Fick. Com base na Teoria da Difusão, supondo um sistema isotérmico e convertendo a concentração de soluto difundente no conteúdo de umidade do sólido em base seca, tem-se a seguinte equação do balanço de massa:

$$
\frac{\partial\left(\rho_{s} X\right)}{\partial t}=\nabla\left(D_{e f f} \rho_{s} \nabla X\right)
$$

Assumindo a difusividade efetiva e as propriedades do sólido constantes, geometria cartesiana, o encolhimento do material desprezível e a transferência de massa unidirecional (direção z), a Equação (1) fica reduzida a forma:

$$
\frac{\partial X}{\partial t}=D_{e f f} \frac{\partial^{2} X}{\partial z^{2}}
$$

A Equação (2) está sujeita às seguintes condições inicial e de contorno:

$$
\begin{aligned}
& \text { C.I }: X=X_{0} \text { em t }=0,0<\mathrm{z}<\mathrm{t} \\
& \text { C.C. } 1:\left(\frac{\partial X}{\partial z}\right)=0 \text { em } \mathrm{z}=0, \mathrm{t}>0 \\
& \text { C.C. } 2: X=X_{e q} \text { em } \mathrm{z}=\mathrm{L}, \mathrm{t}>0
\end{aligned}
$$

A Equação (2), submetida às condições apresentadas, tem sua solução analítica obtida por separação de variáveis (Crank, 1975):

$$
X(t)=X_{e q}+\left(X_{0}-X_{e q}\right) 2 \sum_{n=0}^{\infty} \frac{(-1)^{n}}{\lambda_{n}} \cos \left(\eta \lambda_{n}\right) \exp \left(\lambda_{n}^{2} \frac{D_{e f f}}{L^{2}} t\right)
$$

Em que $\eta$ é o comprimento característico e $\lambda_{n}$ os valores característicos. A umidade média é obtida pela Equação (4), pois em estudos de camada delgada o que se obtém é a concentração média espacial de umidade da célula de secagem ao longo do tempo. 


$$
\bar{X}(t)=\frac{1}{L} \int_{0}^{L} X(z) d z
$$

Substituindo a Equação (3) na Equação (4) e realizando a integração, a umidade adimensional do meio homogêneo $\left(X^{*}\right)$ em função do tempo é dada por:

$$
X^{*}=\frac{\bar{X}(t)-X_{e q}}{X_{0}-X_{e q}}=\frac{8}{\pi^{2}} \sum_{n=0}^{\infty} \frac{1}{(2 n+1)^{2}} \exp \left[-\left(n+\frac{1}{2}\right)^{2} \pi^{2} \frac{D_{e f f}}{L^{2}} t\right]
$$

\subsection{Difusividade efetiva variável}

Efremov et al. (2008) apresentam um método para determinar a difusividade efetiva de experimentos como um parâmetro variável em função do tempo nas condições estudadas. O método combina uma solução analítica da equação de Fick com uma equação semi-teórica derivada para condições pseudo-estacionária. O número de Fourier é obtido pela seguinte relação:

$$
F_{0}(t)=\frac{D_{e f f} t}{L^{2}}
$$

A difusividade efetiva em função do conteúdo de umidade e do tempo de secagem, para baixos valores do número de Fourier $\left(0<\mathrm{F}_{0}<0,08\right)$, pode ser calculada pela seguinte equação:

$$
D_{e f f}=\frac{L^{2}}{\pi^{2 / a} b^{1 / a} t}\left[-\ln \left(X^{*}\right)\right]^{1 / a}
$$

Os parâmetros $a$ e $b$ são estimados através da seguinte equação de cinética de secagem:

$$
X^{*}=\exp \left[-\pi^{2} b\left(F_{0}\right)^{a}\right]
$$

Para valores mais elevados do número de Fourier $\left(\mathrm{F}_{0}>0,08\right)$, o coeficiente difusivo é obtido pela seguinte equação:

$$
D_{e f f}=-\frac{L^{2}}{\pi^{2} t} \ln \left(\frac{8}{\pi^{2}} X^{*}\right)
$$

Com base na teoria do método pseudo-estacionário (Efremov, 1999), a umidade adimensional em função do tempo é dada por:

$$
X^{*}=\frac{1}{1+(t / \sigma)^{m}}
$$

Combinando a Equação (10) com as Equações (7) e (9), chegam-se as expressões finais para o cálculo da difusividade efetiva em função do tempo e da umidade adimensional:

$$
\begin{aligned}
& D_{e f f}=\frac{L^{2}}{\pi^{2 / a} b^{1 / a} t}\left\{\ln \left[1+\left(\frac{t}{\sigma}\right)^{m}\right]\right\}^{1 / a} \quad 0<F_{0}<0,08 \\
& D_{e f f}=-\frac{L^{2}}{\pi^{2} t} \ln \left\{\frac{8}{\pi^{2}}\left[1+\left(\frac{t}{\sigma}\right)^{m}\right]\right\} \quad F_{0}>0,08
\end{aligned}
$$




\section{MATERIAIS E MÉTODOS}

Neste trabalho, foi utilizado um leito delgado de $1 \mathrm{~cm}$ de espessura e diâmetro interno de 9,6 $\mathrm{cm}$ recheado com grãos de cevada (Hordeum vulgare) da variedade BRS Cauê. A espessura do leito foi determinada em experimentos preliminares, realizados com termopares inseridos na entrada e na saída do leito que detectaram uma variação de temperatura menor do que $0,5^{\circ} \mathrm{C}$. A partir destes resultados, a espessura de $1 \mathrm{~cm}$ foi adotada como critério para o estudo da camada delgada. Para obter o conteúdo de umidade inicial do grão quando colhido, foi realizada a reumidificação dos grãos de cevada em imersão por 2 horas em água antes do início de cada experimento. Os estudos de cinética de secagem foram realizados em um secador de leito fixo, onde o meio foi submetido a um escoamento monofásico e ascendente de ar em determinadas condições de velocidade, umidade e temperatura. Nos experimentos, o leito de massa inicial conhecida foi submetido ao processo de secagem e pesado em intervalos de tempo préestabelecidos em um abalança analítica (precisão $1 \times 10^{-3} \mathrm{~g}$ ). A massa seca foi obtida mantendo-se o meio em estufa com circulação de ar a $105 \pm 3^{\circ} \mathrm{C}$ por 24 horas. As condições operacionais nas quais os estudos de secagem foram realizados obedecem às seguintes faixas operacionais: $45 \leq T_{g}\left({ }^{\circ} \mathrm{C}\right) \leq$ $50 ; 0,8 \leq v_{g}(\mathrm{~m} / \mathrm{s}) \leq 4,0 ; 2,9 \leq U R(\%) \leq 26,6 ; 17,6 \leq X_{0}(\%$, base úmida $) \leq 22,1$. A umidade relativa do ar dependeu das condições laboratoriais, e foi determinada diretamente por um termohigrômetro.

\section{ANÁLISE DOS RESULTADOS}

As curvas de secagem apresentadas na Figura 1 (a) e (b) foram construídas de tal forma que fosse possível visualizar os efeitos isolados de temperatura e velocidade do ar de secagem.
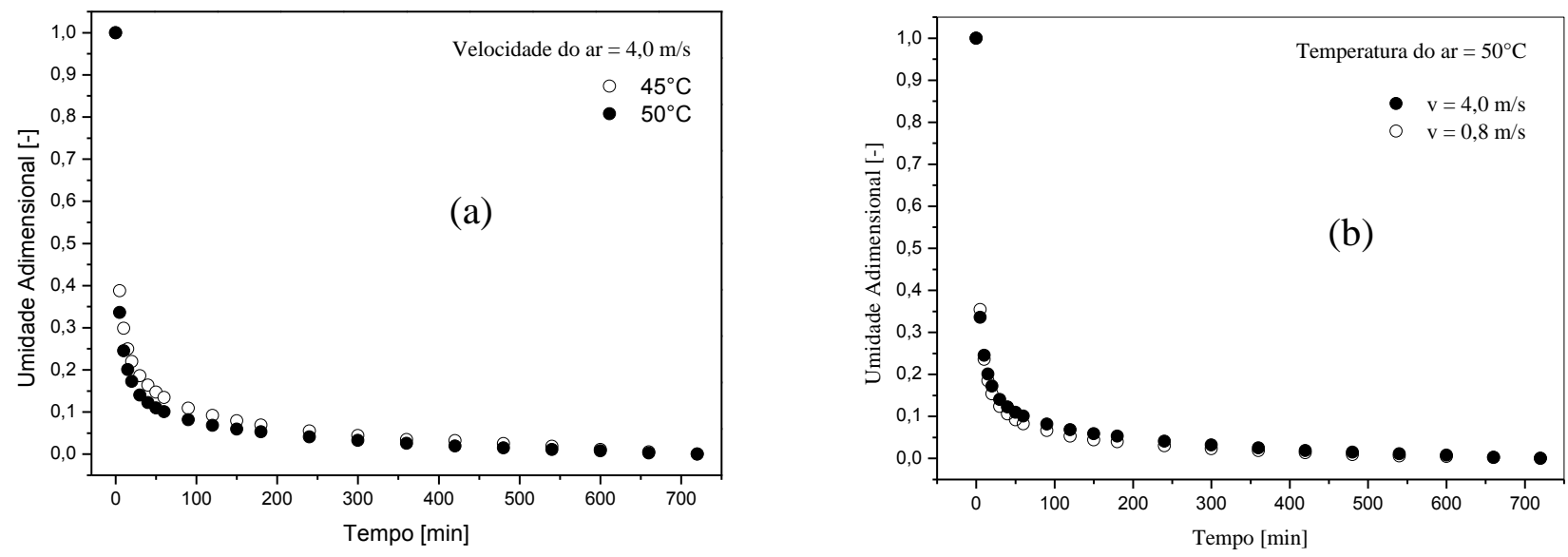

Figura 1 - Dados experimentais de cinética de secagem (a) parametrizado na temperatura do ar e (b) parametrizado na velocidade do ar

Verifica-se na Figura 1 (a) os dados experimentais da cinética de secagem de grãos de cevada nas temperaturas de $45^{\circ} \mathrm{C}$ e $50^{\circ} \mathrm{C}$, expressos pela umidade adimensional em função do tempo de secagem. Observa-se que o aumento da temperatura teve um efeito pouco significativo na redução de umidade do material. O efeito pouco significativo da temperatura no processo pode estar relacionado também a estreita faixa de temperatura utilizada. A variação de $5^{\circ} \mathrm{C}$, 
provavelmente, não foi suficiente para observar a influência da temperatura na secagem do material através de diferenças visíveis entre as curvas. Já na Figura 1 (b), os dados experimentais de cinética de secagem foram expressos também através da umidade adimensional em função do tempo de secagem, mas com temperatura constante e velocidades do ar de secagem de $0,8 \mathrm{~m} / \mathrm{s} \mathrm{e}$ $4,0 \mathrm{~m} / \mathrm{s}$. Pode-se observar que a velocidade do ar de secagem não exerce influência significativa, indicando que a transferência de massa no interior dos grãos de cevada (difusão) corresponde à etapa limitante durante o processo de secagem, sendo o efeito convectivo desprezível.

Na Figura 2 é apresentada uma comparação típica entre os dados observados e preditos pelo modelo difusivo para a situação na qual a difusividade é tratada como parâmetro constante. $\mathrm{O}$ modelo difusivo foi resolvido pelo método de separação de variáveis (Crank, 1975) em que as seguintes considerações foram feitas: umidade inicial uniforme, encolhimento do sólido desprezível e conteúdo médio de umidade. Foram utilizados 2000 termos na série, o que proporciona um erro de $0,01 \%$ no instante inicial da secagem $(t=0)$. A difusividade efetiva foi estimada com base nos critérios dos mínimos quadrados.

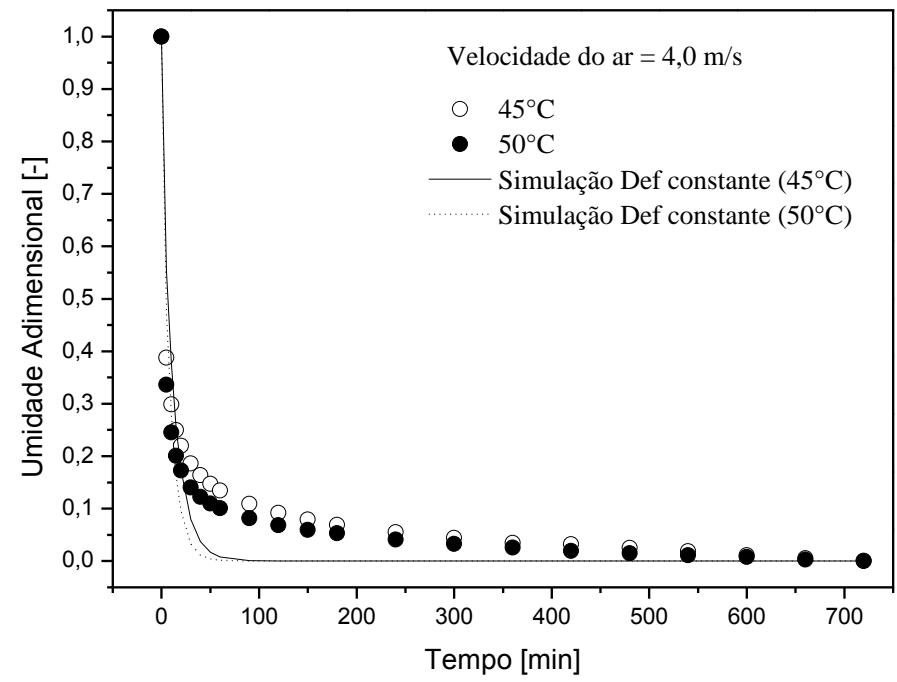

Figura 2 - Dados de cinética de secagem observados e preditos pelo modelo difusivo quando a difusividade efetiva é considerada um parâmetro constante.

Com base nos resultados apresentados, é possível observar que o ajuste proporcionado pelo modelo difusivo com $D_{\text {eff }}$ constante não é satisfatório, subestimando os dados na etapa intermediária até o término do processo de secagem. Possivelmente, os desvios encontrados entre os dados observados e preditos podem estar relacionada ao fato de considerar a difusividade efetiva como um parâmetro constante. No modelo difusivo com $D_{\text {eff }}$ constante, os dados experimentais são ajustados considerando um valor médio do coeficiente difusivo, mas este parâmetro pode assumir diferentes comportamentos, sendo uma função, principalmente, do conteúdo de umidade e da temperatura do material.

Assim, com o objetivo de investigar a dependência da difusividade efetiva com o tempo de secagem, um estudo com base no modelo de Efremov et al.(2008) foi realizado. A Figura 3 apresenta os dados experimentais e os dados preditos de cinética de secagem pelo modelo difusivo quando a difusividade é estimada como um parâmetro variável (em função do tempo de secagem). 
Observam-se ainda pequenos desvios, sobretudo para os instantes finais da secagem $(\mathrm{t}>500 \mathrm{~min})$, mas quando comparado com a simulação para $D_{\text {eff }}$ constante, Figura 2, os dados de umidade em função do tempo são mais bem representados usando-se a abordagem pseudo-estacionária, em que a difusividade efetiva é considerada em função da umidade do sólido e do tempo de secagem, um parâmetro variável.

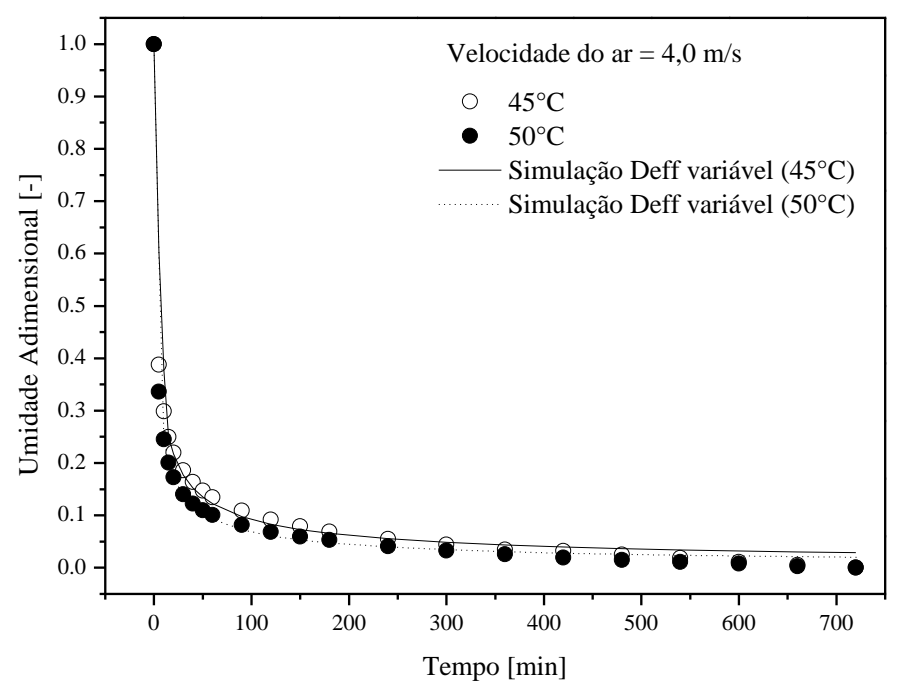

Figura 3 - Dados da cinética de secagem observados e preditos pelo modelo difusivo quando a difusividade efetiva é considerada um parâmetro variável com o tempo.

A Figura 4 apresenta os dados de difusividade efetiva em função do tempo calculados pelas Equações (7) e (9) e as curvas preditas são geradas pelas Equações (11) e (12). Verifica-se que os dados preditos representam qualitativamente o fenômeno de difusão de umidade para uma primeira análise. Os valores de difusividade efetiva em função do tempo de secagem, obtidos pela formulação desenvolvida por Efremov et al. (2008), representaram resultados mais consistentes quando comparado com um valor constante de difusividade efetiva. Inicialmente, a $D_{\text {eff }}$ variável predita é nula em $t=0$, quando se inicia a remoção de água presente nos grãos, a difusão se eleva rapidamente até atingir um valor máximo, o que caracteriza o período em que o material apresenta maior concentração de água, e logo após, quando o grão vai atingindo um baixo grau de umidade e o tempo de secagem é maior, a difusividade efetiva decresce até o momento em que a taxa de secagem é igual a zero. 


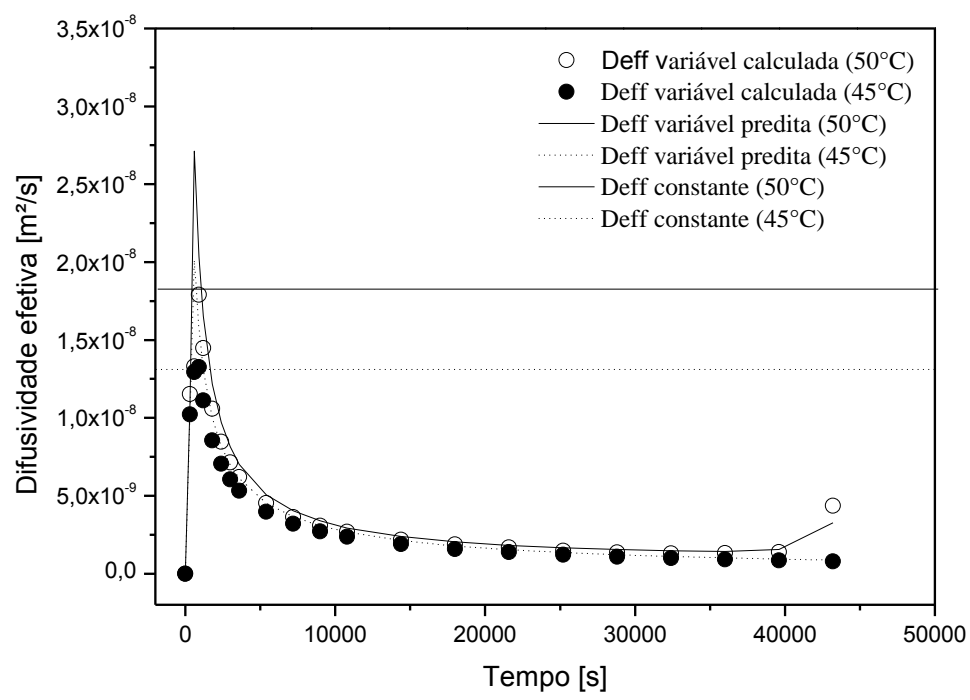

Figura 4 - Dados da difusividade efetiva em função do tempo

\section{CONCLUSÃO}

Neste trabalho foram investigados os mecanismos de transferência de massa presentes na secagem de grãos de cevada em secador de leito fixo e camada delgada. Com os resultados obtidos, observou-se que o modelo difusivo não representou adequadamente os dados experimentais de cinética de secagem quando a difusividade efetiva é considerada um parâmetro constante. O coeficiente de difusão estimado apresentou dependência com o tempo da secagem, possivelmente devido a influência das propriedades do sólido, principalmente da umidade. Quando a difusividade efetiva é considerada um parâmetro variável e em função da umidade do sólido e do tempo de secagem, os resultados preditos foram mais satisfatórios.

\section{NOMENCLATURA}

$a \quad$ Parâmetro de ajuste das Equações (7), (8) e (11) [-]

$b \quad$ Parâmetro de ajuste das Equações (7), (8) e (11) [-]

$D_{\text {eff }} \quad$ Difusividade efetiva $\left[\mathrm{m}^{2} / \mathrm{s}\right]$

$L \quad$ Espessura da célula de secagem [m]

$m \quad$ Parâmetro hidrodinâmico [-]

$t \quad$ Tempo de secagem [min]

$T_{g} \quad$ Temperatura do gás $\left[{ }^{\circ} \mathrm{C}\right]$

$v_{g} \quad$ Velocidade do gás $[\mathrm{m} / \mathrm{s}]$

$X \quad$ Umidade do sólido em base seca $[\mathrm{kg} / \mathrm{kg}]$

$X_{0} \quad$ Umidade em $\mathrm{t}=0[\mathrm{~kg} / \mathrm{kg}]$

$X_{e q} \quad$ Umidade de equilíbrio dinâmica [kg/kg]

$X^{*} \quad$ Umidade adimensional [-]

$\sigma \quad$ Tempo característico [s] 


\section{REFERÊNCIAS}

BRASIL. Embrapa Trigo. Cevada. Dispnível em: <http://www.cnpt.embrapa.br/culturas/cevada〉. Acesso em: 08 out. 2013.

BRIGGS, D. E.; BOULTON, C. A.; BROOKES, P. A.; STEVES, R. Brewing: Science and Practice. New York: CRC Press, 2004.

CRANK, J. The mathematics of diffusion. Claredon Press: Oxford, 1975.

EFREMOV, G. Modified quasi-stationary method for drying kinetics of hygroscopic materials. $J$. Eng. Phys. Thermo., v. 72, p. 420-424, 1999.

EFREMOV, G.; MARKOWSKI, M.; BIALOBRZEWSKI, I.; ZIELINSKA, M. Approach to calculation time-dependent moisture diffusivity for thin layered biological materials. Int. Commun. Heat Mass Transf., v. 35, p. 1069-1072, 2008.

KUNZE, W. Technology Brewing and Malting. Berlin: Versuchs und Lehranstalt für Brauerei in Berlin (VLB). 2004.

MORI, C. de; MINELLI, E. Aspectos econômicos e conjunturais da cultura da cevada. Disponível em: 〈http://www.cnpt.embrapa.br/biblio/do/p_do139.pdf>. Acesso em: 08 out. 2013.

TUNES, L. M. de; BARROS, A. C. S. A.; BADINELLI, P. G.; GARCIA, D. C. Diferentes épocas de colheita e qualidade fisiológica de sementes de cevada. Revista Brasileira de Sementes, v. 32, $\mathrm{n}$ 2, p 042-048, 2010. 